\title{
Family Policy Motives behind Proposals in the Finnish Parliament
}

BY LEENA SUOMINEN

Family Council

In Finland, family policy legislation can be said to have begun during the 1930's, a decade which also elsewhere in Europe saw the actual birth of family policy. The 1940 's, in turn, could be called family policy's expansion period; this decade was the time when many forms of family support were created, the most important of which was possibly the general child subsidy.

During the past few decades, the family policy legislation of Finland has become rather desultory: around a dozen different measures have been instituted to support families. However, since the end of the 1960's there have been attempts to simplify this random system and cut down on the number of different benefits: for example, several family policy committees and working groups have given proposals for the rationalization of measures, and during the 1970's some laws regarding benefits have been repealed, and the support granted on the basis of these laws has been tied onto other benefits.

The focus of this study ${ }^{1}$ is to clarify the motives behind the family policy of Finland at different times. A concrete example of this focus is the following: first of all, child subsidies could be motivated on the grounds that through them, in the name of justice, the expenditures children cause their parents could be compensated; secondly, child subsidies could have been regarded as necessary to keep the growth of population stable; thirdly, the utilization of child subsidies could be supported on the grounds that through them, it was believed, one could increase the consumption of families with children, and through this, one could affect the entire national consumption. These different motives could have been presented separately or in conjunction with each other.

\section{The connections between family policy and social development policy}

In defining social development policy as an activity, at least in Finland one is accustomed to dividing it into different sections. The sections that researchers usually refer to are economic policy, social policy and cultural policy. According to Armas Nieminen, one has begun to use the term social development policy to signify the all-around development of the conditions in

1 This article is based on a study made by the author: Leena Suominen. Perhepolitiikan perustelut Suomessa. The Population Research Institute. Series B 36. 1975. 
society (Nieminen 1972, 6), and according to Leo Paukkunen the goal of social development policy is the increase of well-being, and its forms of activity are the three sections mentioned above (Paukkunen 1967, 17-18).

The connection between family policy and economic policy was seen to lie in the fact that the family is supported so that the need for a labour force is satisfied - labour, after all, is an essential factor of production - or the stabilization of consumption is achieved, something which is important in the light of market conditions, especially during a slump, when the redistribution of income funneled to households is expected to increase the total consumption and have a stimulating effect on the economy. In addition to production and consumption, economic savings are also important from the standpoint of family policy, for example when one attempts to utilize measures to cut down on future expenses.

Family policy as social policy was seen to mean, on one hand, the vertical equalization of income, a leveling out between poor and rich families, and on the other hand, the horizontal equalization, which could first of all be an equalization between families with children and families without, and on the other hand, an equalization between large and small families with children, and finally, an equalization between families with children in the city and in the country.

Culture can also be given a wide interpretation, such as that given by Antti Eskola when he said, »The term culture is often applied to an entirety that is composed of knowledge, beliefs, art, conceptions of morals, law, tradition and all other abilities and customs that an individual has adopted as a member of the society.» (Eskola 1964, 4). In this way, the connections between family policy and cultural policy could be seen to lie in, among others, those measures that were intended to preserve the family concept belonging to Western culture, in connection with which the position of the family as the basic social unit was emphasized. Furthermore, a cultural policy aspect of family policy was seen to lie in effecting the development of children and young people. Through this, the family was supported in its role in rearing children. Further aspects were seen in questions related to the role of women, for example the equal right of women alongside of men to, for example, take part in work outside of the home, and, on the other hand, the position of the mother in the family.

From the viewpoint of population policy, essential matters have been questions linked to the size of the population and the quality of the population. Factors affecting population size are the birthrate, the deathrate, and migration. Population quality, in practice, has meant the standard of health of the population; for example, the Committee on the Equalization of Family Expenses included among the qualitative population goals an increase in the standard of health (Perhekustannusten tasauskomitean mietintö 1966, 21). From the viewpoint of the support of families these are all important - migration, however, only if one attempts to support families so that young families with children would not emigrate. 


\section{The data and the classification of the data}

The proposals, especially the family policy proposals, presented by members of Parliament from 1934 to 1973 formed the basic data of the study. According to the constitution of Finland, the Parliament in session represents the people, to whom the power of the State is seen to essentially belong. For this reason, the Parliament has been regarded as the most important political institution of Finland. In Parliament, matters can be initiated, basically, through two channels: as a Government proposal or as a proposal initiated by members of Parliament.

Generally, a number of members sponsor a proposal. However, the first member to sign the proposal is the main initiator and sponsor. The number of proposals made by a Parliamentary faction or group of factions is rather small, and so most of the proposals are so-called private proposals.

The use of proposals as the data was hindered by the fact that they can be regarded as having propagandistic overtones, and may be seen to be intended to woo the electorate. This feature became apparent in that the number of proposals was clearly largest during the Parliamentary sessions immediately before and immediately after elections. In the former case, the intentions is to create favourable publicity, and in the latter case, the purpose is to make good on the promises given to one's voters (Nousiainen 1961, 65). This was taken into consideration in the study by comparing the proposals to the nearness of elections. On one hand, it was to be expected that in the expressed motives the members were "serious», while on the other hand, in the proposed measures they exhibited a greater tendency towards "wooing"; for example, they could easily unrealistically inflate the size of the benefits.

All the proposals made between 1934 and 1949, a total of 95 proposals, were included in the data. On the other hand, the number of the proposals that were made between 1950 and 1973 was so large that a sample was taken for inclusion in the data. The sampling method used in this study was systematic sampling, as this method allows the units taken into the sample to evenly »cover» the population (Manninen 1972, 33). The proposals made during each year were collected in keeping with the alphabetical order of lists of items, and so each proposal had an equal chance of being included. In addition, the motives of the proposals and the alphabetical order were not related with each other. The final study data consisted of 487 proposals, or $37,8 \%$ of the basic data.

In the classification of the data, content analysis was used in the following manner:

- It was the most important aid in the assembly of the data, as it was used to concentrate the information in the proposals into a more exact form.

- In the classification, only the evident contents of the proposals were used, in other words "pure content analysis» was used, in which no attempt was 
made to read between the lines or reach conclusions except on the basis of what was clearly said in the proposal.

- The classification was based on the social development policy aspect structure of family policy; in other words, the point of departure was more a solution based on the frame of reference than on the data.

\section{The objects and the initiators of family policy proposals}

It appeared as if the members of Parliament had concentrated on a few forms of support. Of the over twenty forms of benefits that were examined, only five were the focus of about half of all of the proposals. These five were day care for children, child subsidies, vacation activity for mothers and children, tax reliefs and home establishment loans. It was surprising that maternity and child clinic work, which is regarded as an important protector of the health of mothers and children, was only rarely the focus of proposals by members.

Very rarely have members of Parliament presented large, wide-ranging proposals for reform of the system of equalizing family costs. This is possibly due to the fact that members and parties have not had a clear general family policy program. One could, of course, suppose that this feature, the fact that interest has been focused on quite limited measures, is due to the fact that the members of Parliament have been aware of the insignificance of the political effect of these proposals. But this latter alternative has been shut out in the sense that it has been specifically noted that it is possible to use proposals to bring a matter demanding reform to the attention of the Government.

It is apparent that members belonging to parties on the left ${ }^{2}$ have been more active than right-wing party members as supporters of family policy: during almost every period, the number of proposals made by the former has composed ovar half of all family policy proposals, despite the fact that in Finland, the former outnumbered the latter only during the $1966-1969$ term. The number of family policy proposals made by all of the so-called large parties decreased relatively during the period under study. The so-called small parties have shown more interest towards family policy that what could be presumed on the basis of the number of seats held.

At the beginning of the period in question, the members chosen from northern Finland have, relatively speaking, been very interested in family

2 The following parties are regarded as being on the left: the Finnish People's Democratic League (represented since 1945), the Social Democratic Opposition (19581961), the Workers' and Small Farmers' Social Democratic League (1962-1969) and the Social Democratic Party. Other parties are regarded as being on the right. 
policy, while on the other hand those from Central Finland have given proposals supporting families noticeable less often - again, relatively speaking. During the 1950's, the members from southern Finland have been active supporters of family policy. These results seem to illustrate that the members from Central Finland do not have the same "natural» interest in family policy than do the members from South and North Finland, who represent areas where families have their own special problems.

At no time have women members comprised even one fourth of all the members. Even so, during all the sessions they have made over half of the family policy proposals. Women members have displayed exceptional activity - taking into consideration also the absolute number of proposals - during the years 1945 to 1949 ; during this period they made more than five times more proposals regarding the support of families than what could be expected on the basis of their number. If one should examine the number of proposals alone, the activity of the women members was greatest at the end of the 1950's, but at this time there were more women in Parliament than at the end of the 1940's. Therefore, at least this study indicated that the interest displayed in family policy is dependent on sex.

\section{Family policy as social policy}

In the social policy motives given in the study, the term sequalization of differences in the standard of living" was used. This term refers above all to the redistribution of income or to an equalization of the possibilities for consumption; in general, an equalization of differences apparent in the living circumstances of two groups that are interesting from a family policy viewpoint.

In family policy proposals, reference has been made quite often to the necessity of a vertical equalization of differences in the standard of living. This motive played a very important role at the very beginning of the study period, during the first years of Finnish family policy, when about two-thirds of all the family policy proposals emphasized the necessity of supporting poor families.

In general, members of Parliament have motivated their family policy proposals to varying degrees with demands based on support needed by families with children. All in all, reference has been made to this motive scarcely half the number of times reference was made to support needed by poor families. An interesting feature in examining this horizontal equalization motive is that it was brought up both during the post-war years and during the most recent years. Especially this more recent interest in all families with children has been directed towards young families; one has begun to emphasize that the 
position of young families with children is the most difficult in society, as their income is lowest but their expenses highest.

Members of Parliament have, to a steadily decreasing degree, motivated family policy forms of support with the view that these measures can be used to support large families. During the present decade, there has been almost 10 times less use made, in motivating these proposals, of arguments demanding equalization between large and small families than there was during the 1930's. This noticeable decrease is evidently a symptom of large families becoming more and more rare in Finland, and so support given to these families is not so burning a question as it was during the beginning of the study period.

There seems to have been a noticeable change at the end of the 1940's and the beginning of the 1950's in the presentation of proposals concerning support of families in the country: during the 1940's, every fifth family policy proposal focused attention on the necessity of levelling off differences in the standard of living between families living in different types of administratory communes, while during the 1950's this point of view was brought up in only a very few cases. This low interest in the position of families in the country seemed to then become a permanent feature in the family policy of the 1950's through the 1970 's.

In examining all of the social policy motives together, it was noted that throughout the study period they have been used quite often, and relatively more often during the 1930's and the beginning of the 1960's: during these two periods, only one fifth of the proposals did not make any reference to some social policy reason.

Differences in the use of social policy motives between members of Parliament belonging to parties on the left and on the right was seen most clearly in the use of the motive of levelling off standard of living differences between rich and poor families: members on the left made noticeably more reference to this matter than did those on the right. The average differences between these two blocs were not as clear in connection with the other special social policy motives.

A detailed classification of the use of social policy motives in accordance with the regional background of the members of Parliament showed a variance which can be regarded as interesting. Apparently, members from Central Finland have been very little interested in general in the position of families with children, while members chosen from southern Finland have referred to this motive in about one third of their proposals. This result should be taken specifically in connection with the fact that members from Central Finland made, during the first decades examined, family policy proposals to a degree smaller than what could be expected by numbers alone. Supporting poor families and supporting large families seemed to have been matters of about equal interest for members from Central and North Finland. North Finland members seemed to have been the only ones interested in the position of families in the countryside. 


\section{Economic policy motives for family policy}

The consumption-increasing effect of family policy income redistribution, a view presented by Pekka Kuusi in his book 60-luvun sosiaalipolitiikka» ("Social Policy of the Sixties") was not mentioned in a single one of the motives of the almost 500 family policy proposals studied. This is a surprising result in that Pekka Kuusi specifically stated that family policy income redistribution is probably a rather efficient consumption stimulus, at least it is more efficient than income redistribution in favour of elderly people (Kuusi 1968, 194). It is self-evident that during the beginning and middle period of the study period this view of sactivating the passive population" could not have surfaced, as it was apparently never discussed in public. But it is surprising that even after Pekka Kuusi's program declaration appeared members of Parliament made no reference in their proposals to the stimulating effects family policy measures have on total consumption.

Nor were family policy measure factors connected with production aspects regarded by the members as very important; however, they were mentioned at least a few times. During the post-war reconstruction period motives dealing with production were relatively important: in one fifth of the proposals related to family support, points of view tied in with the acquisition of a labour force and the increase of production were emphasized. Economic savings motives have above all emphasized the rationalization of state economy expenses, even decreases in these. In individual proposals dealing with family policy measures, this motive has usually appeared in the form which emphasized the profitability of some measures in the long run. Examples of this have been child guidance clinics and vacations for mothers, both of which would help in preventing institutional care expenses from becoming a burden to society, and would help in directing funds in a more sensible manner. This motive was not emphasized more strongly at times to the same degree as was the point of view related with production; however, even this motive was the focus of more attention at the end of the 1940's.

In motivating family policy proposals, members of Parliament have clearly made less references to general economic points of view than they have to production or economic savings. Thus, in presenting economic policy aspects, members have attempted to utilize them in a more specific form. An increase of interest during the post-war reconstruction period can also be seen in connection with the use of unspecified general economic viewpoints in proposal motivation.

In general, it can be said of economic policy motives that they were rarely used in Finland in connection with support to families. Only the 1930's and the 1940 's were exceptions to this low interest in economic policy. Especially in comparison to social policy motives there has been little use made of economic policy motives. 
Members belonging to parties on the right proved to be more economic policy oriented in their family policy proposals than were leftist members. We have already mentioned that members belonging to parties of the left were more interested in support to families for social policy reasons. In examining the use of individual economic policy motives, it can be seen that members belonging to the right more clearly than those belonging to the left brought up the aspect which stressed the necessity of economic savings.

\section{Cultural policy aspects in family policy}

In the presentation of motives connected with the upbringing of children there do not seem to be relatively large variations except during the beginning of the 1960's, when only one out of all the 68 proposals in the data brought up the point of view that families should be supported so that they could better bring up their children. It is rather interesting that immediately after the war aspects relating to child rearing were brought up in about every fifth family policy proposal. This is a rather large amount, especially when we consider the large absolute amount of proposals during this period.

On one hand, it was typical of the end of the 1940's that there were very many young children; and on the other, the system of child subsidies, an important family policy form of support, was taken into use. Furthermore, according to the study it was typical of this period that a large number of proposals regarding the day care of children and vacation activity for mothers were made. It was specifically in these proposals that attention was directed to questions related to bringing up children. In child day care proposals demands were raised according to which children should not be left without proper care when their mother was at work, and the day care facilities should be as favourable as possible to the development of the child.

It is surprising that family policy proposals of the 1960's and the 1970's were not motivated relatively more often than before with points of view stressing the equality of women. This indicates that during the past decade family policy was not closely connected with questions related to the position of women, something which otherwise was topical. This result can probably be partly explained by the fact that in the questions related to the position of women which appeared in the study, no mention was made of the housewife-working mother dimension; instead, the issue was in general the equality of women with men. The discussions on the position of women which took place during the 1960 's and the 1970's have apparently dealt principally with the equality or the inequality of these two groups of mothers. These aspects did not appear to an equally large extent in family policy proposals as did the questions related to the position of women which concerned themselves with the inequality of men and women - husband and wife or mother and father. 
During the end of the 1940's and the beginning of the 1950's relatively greatest attention was paid to the position of women. During the proposals of this period it was emphasized on one hand that women must do an inordinately large amount of work at home - which especially in large families led to over-exertion. It was specifically the removal of this inequality - or at least alleviation of its consequences which was the goal of family policy measures, the most important of which were home help service and vacation activities. On the other hand, it was noted that on the employment market women were not equal with men for example because of the child care question, and therefore one believed that by arranging day care for children one could ease the situation. During the past years this latter problem has been mentioned, but the former, that of over-exertion, has not. All in all, during the final period of the study period relatively less attention was paid to the position of women when compared to the late 1940's and the early 1950's.

Apparently, members of Parliament have not regarded family policy measures as necessary for the reason that through them, one could preserve the central social institution, that of the family. In other words, the members have not been interested in the family for the familys sake. At least, this viewpoint has not been presented directly; it is a completely different matter what members have thought or intended in the background. But in this study, as noted when presenting the principles of data classification, no reading between the lines has been attempted.

All in all, cultural policy motives for family policy have been rather more common than have economic policy viewpoints - an exception, of course, are motives related to the family's position as a basic unit - but cultural policy motives were clearly less common than social policy motives. Cultural policy motives were most common at the end of the 1940's, in other words at the same time when economic policy aspects were often alluded to.

There were scarcely any differences evident in the presentation of cultural policy aspects between members chosen from different parties and from different regions. This was surprising in that, as noted elsewhere, bourgeois parties pay more attention to the position of the home and the family, and to questions related to young people. This, however, did not come up in this study; instead, both left-wing and right-wing parties seemed to pay equal attention to such matters as the point of view that children should be brought up to be functioning members of society, and that women should be equal with men.

Guidance, home help and other services to aid families - social services in general - have been motivated to a large degree with cultural policy points of view, or else in proposing financial support to families reference has rarely been made to cultural reasons. This is understandable when taken in conjunction with the fact that social services specifically offer families nonmaterial well-being, and through them, it is possible to, among others, develop the customs prevalent in society and in general take into consideration culture 
in its broad interpretation. A comparison of the individual cultural policy motives with the type of measure proposed shows that when proposing social services for families consideration has been made especially of points of view connected with the socialization of children and the position of women. It became apparent that women members of Parliament referred to cultural policy points of view in about a third of all their proposals, while men members made similar references in less than one fifth of their proposals. After a more detailed examination the differences seemed even more typical: women, more often than men, motivated their proposals with the necessity of taking care of the upbringing of children. It is naturally clear that they have paid specific attention to the position of their sex, and they have wanted to better it also through family policy measures.

\section{Family policy as population policy}

It has been presented in several different connections that during the 1930's one was interested in Finland in questions linked with the size of the population, and this study brings one to the same conclusion: in the family policy proposals at the end of the 1940's and the beginning of the 1950's problems connected with the size of the population played a relatively larger role than later on. Strictly speaking, these population aspects did not appear until the last years of the 1930's - in other words, not immediately after the appearance of Gunnar Modeen's famous prognosis. It is also interesting to note that to at least some degree members of Parliament have been interested, during the past few years, in the population development in Finland. During the 1950's and the 1960's they did not take a stand at all in their family policy proposals on this matter.

Motives connected with the birthrate seemed to have been the focus of attention equal to that of the size of population. Family policy proposals showed that especially during the war, birth rate aspects were at the fore; it is true, though, that during this period there was a low absolute number of proposals. This war-time interest in the development of the birth rate is probably due to the very low birth rate of the time, and partly due to the population policy mode of thinking brought up during the 1930's.

In the same way as unspecific economic and cultural policy motives decreased, general population policy motives were also continuously on the decrease. During the 1960 's, however, such general population policy viewpoints did appear in a few proposals. It is evident, even so, that if population policy motives appear in family policy these days, they are expressed in an exact manner in connection with either the birth rate or the size of the population.

In family policy, motives connected with public health seemed to have decreased on the whole. This decreasing trend can partly be understood by recalling that health services were greatly developed towards the end of the 
study period in Finland. It is clear that at a time when there were no general health service arrangements, family policy measures had important public health goals. One should especially mention maternity and child clinics, maternity assistance and vacation activities for mothers and children, through which, for example during the post-war years, one was apparently able to significantly affect the general level of health.

All in all, of the family policy motives which can be seen to be related to population policy, it should be noted that they display great variations at different times: now and then population policy aspects were ignored completely. In examining all population policy motives, credence is given to the belief that during the late 1930's and the early 1940's, attempts were made to support families specifically for population policy reasons. In comparison with the family social support motives presented above, it seems as if population policy aspects in Finnish family policy were about as rare as were economic policy motives.

In the same way as cultural policy aspects, also population policy aspects were presented more often in connection with proposals regarding forms of services to families. Of the individual population policy motives of family policy, especially the increase of the level of health - related motives were connected with proposals on social services. Here it is apparent that of the family social services for example maternity and child clinic activity, home help service and even the day care of children have self-evident public health aspects.

Apparently the parties on the right have emphasized more than have the parties on the left the effects of family policy measures on population development. Of the individual population policy motives there seems to have been the following difference between members belonging to different parties: those belonging to large parties were especially interested in public health aspects.

\section{Conclusions}

Finnish members of Parliament have, in their family policy proposals, rarely presented motives connected with broader social matters. When such motives were presented, they were principally of a social political nature, especially demanding an economic equalization of the differences between the rich and the poor.

The earliest point of departure in Finnish family policy has been social, and thus not connected with the development of the population. Not until the end of the 1930's were population policy aspects presented, in other words, somewhat later than in Sweden, where already in the mid-30's attempts were made to better the position of families specifically in order to improve the birthrate. In Sweden at the end of the 1940 's the central matters in family policy were on one hand social motives and on the other hand motives referring to the position of the family as a basic unit - in other words, connected with culture 
(Statens offentliga utredningar 1967, 100-102). This, in a way, was also the case in Finland: support of families was regarded as important not only for social policy reasons but also for aspects relating to the care and raising of children. Furthermore, at the same time economic motives were presented in Finnish family policy.

In Sweden, population policy questions again became the focus of attention at the beginning of the 1950's (Statens offentliga utredningar 1967, 102), but this was not the case in Finland. In Finland, population policy reasons were rarely used in motivating family support: during the 1950's and the 1960's one did not speak of the birth rate in connection with family policy at least in Parliament. Not until the 1970's have members of Parliament begun to focus attention on the development of the population of Finland, and at the same time have attempted to affect it through the use of family policy means of support. During the 1960's and the 1970's, a central feature of the family policy of Sweden has apparently been the social policy point of departure, something that was dominant in Finland already from the beginning of the 1950's.

\section{References}

Eskola A., Yhteiskunnan rakenne ja toiminta. Kuusi päivää kansalaisajattelua. Henkisen maanpuolustuksen suunnittelukunnan julkaisuja n:o 2.

Kuusi P., Social Policy for the Sixties. Porvoo 1968.

Manninen P., Otantamenetelmät. Tampereen yliopiston tutkimuslaitoksen monistesarja C: 19, 1972.

Nieminen A., Yhteiskuntapolitiikan ja sosiaalipolitiikan käsite, tavoitteet ja ala. Oy Yleisradio Ab:n sosiaalipolitiikan kurssi. Helsinki 1972.

Nousiainen J., Eduskunta aloitevallan käyttäjänä. Porvoo 1961.

Paukkunen L., Yhteiskuntapolitiikka - yhteiskuntasuunnittelu. Jyväskylän yliopiston yhteiskuntapolitiikan laitoksen moniste n:o 1/1967.

Perhekustannusten tasauskomitean mietintö 1966: A 7.

Statens offentliga utredningar 1967: 52. Barnbidrag och familjetillägg. Stockholm 1967. 